\title{
Towards an organisational model of 'interface' university structure as a means of serving Lifelong Learning needs
}

\author{
Pencho Mihnev \& Roumen Nikolov \\ Centre of IST, Sofia University “St. Kl. Ohridski”, 125 Tzarigradsko shosse blvd., bl. 2, floor \\ 3, 1113 Sofia, Bulgaria.
}

pmihnev@fmi.uni-sofia.bg; roumen@fmi.uni-sofia.bg,http://www-it.fmi.uni-sofia.bg/cist

\begin{abstract}
The paper conceptualises on the experiences of the Centre of Information Society Technologies (CIST), Sofia University, Bulgaria, in serving the learning and training needs of non-university audiences who fall in situations that can be described as lifelong learning-determined. In developing this conceptualisation we use the research findings and policy agendas in two distinct areas - Lifelong Learning, and Higher Education Systems. More specifically we explore the organisational and management issues and challenges of the quite interesting situation of a structure behaving "in between" the market shaped lifelong learning demands, and the rules and practices of "classical university" structures to which CIST is subordinated. As a result of these three streams of thought and practice we outline an 'interface' model of university interdisciplinary structure, which aims to explicitly meet the demands of the lifelong learning market.
\end{abstract}

Key words: higher education, learning demands, learning delivery, Lifelong Learning,management, organisation, service provider

\section{INTRODUCTION}

Sofia University "St. Kliment Ohridski" is the first and the largest school of higher education in Bulgaria. Today it has more than 35,000 students 
studying in 76 Bachelor's and over 200 Master's degree programmes. Since its establishment the university has always played a very important role for the development of the country. However the university experiences a lot of challenges related to the overall transformation of the economic and social system in the country, the changing models of education, and the new role of the universities in the knowledge-based society. Sofia University is also challenged by the opportunity to be actively involved in the development proposed by the Bologna Declaration European Space of Higher Education (Nikolov 2002; p.1).

The Centre of Information Society Technologies (CIST) was created in 1996 as an extension of the Department of Information Technologies, Faculty of Mathematics and Informatics. It is an interdisciplinary research and training institution, motivated by the challenge of supporting the development, introduction and wide use of Information Society Technologies (IST). This challenge is addressed by performing high-quality research, design and implementation of IST-based systems, and by the design and delivery of 'learning technology'-rich and ICT-supported training to various groups of learners, and variety of institutions and society groups. CIST is designed as a flexible junction between the university, the academic community, local community, industry, NGOs and policy makers, coordinating their efforts at spreading the overall use of, and excellence in, IST (CIST 2002; pp. 1-2).

\section{LIFELONG LEARNING}

The knowledge-based economy relies primarily on the use of ideas and knowledge rather than physical abilities of a person, and on the application of technology rather than the transformation of raw materials or the exploitation of cheap labour (World Bank 2002b, p.ix). This has implications for the demands placed on learning by the labour market and the society on citizens with respect to the knowledge and skills necessary in life. Thus, it is important to equip people to deal with these demands. The most promising way to assure this is lifelong learning.

We will use the lifelong learning definition proposed by the European Commission's "Memorandum on Lifelong Learning" (Commission of the European Communities 2000):

"All learning activity undertaken throughout life, with the aim of improving knowledge, skills and competencies within a personal, civic, social and/or employment-related perspective." 
Crucial for the success and sustainability of any lifelong learning system is to put all policies, strategies, and activities in an overall framework of incentives to all concerned (World Bank 2002b).

\section{LIFELONG LEARNING DEMANDS UPON THE LEARNING DELIVERY STRUCTURES}

Lifelong learning places new demands on the educational institutions and learning providers. Several broad groups of demands can be identified, also high in the political agenda (European Commission 2001, 2002; World Bank 2002b):

- Learner skills demand (person-, labour market-, or society-conditioned):

- "Technical" skills (literacy, foreign language, mathematics, science, ICT skills, information processing, problem-solving, analytical skills);

- Interpersonal skills (teamwork, leadership, communication skills);

- Methodological skills (learning to learn, pursuing lifelong learning, coping with risk and change).

- 'Essence of learning' demand:

- Definition and aims of learning;

- Culture of learning;

- Variety of delivery forms and contexts.

- Institution management demand:

- Resourcing;

- Customers' needs awareness;

- Matching opportunities to interest;

- Dealing with change and innovation;

- Entrepreneurship and risk management;

- Partnership approach (internal and external).

- Accessibility demand:

- Valuing all types of learning (formal, non-formal, and informal);

- Facilitating access;

- Social inclusion.

- Demand on consumer protection and fairness:

- Quality assurance;

- Assessment and certification (non-traditional forms of learning);

Awareness of available providers and learning pathways.

These demands upon the delivering institutions require an adequate response in order to truly serve the learners' needs and to be competitive in the learning market. 


\section{THE NATURE OF HIGHER EDUCATION INSTITUTIONS}

Higher education (HE) institutions are social structures that have as their main activity the processing and development of advanced knowledge, enrichment and dissemination of the world's intellectual heritage, and the education of the intellectual human potential of the nations and the world (Clark 1983, p.11). There are three groups of main activities of the HE institutions - research, teaching, and services. We will consider in more detail how teaching and services are dealt with in the work of $\mathrm{HE}$ institutions.

For the purposes of the lifelong learning provision analysis we will briefly look at the features of the "classical" HE institutions with respect to their:

- Work organization;

- Beliefs (norms and values);

- Authority (decision-making processes, and power distribution and exercising);

- Processes of change (innovation).

The organisation of work at a HE institution is arranged in separate scientific disciplines and is linked in the form of a "loosely coupled system". It is bottom heavy, adaptive and sustainable. The organisational fragmentation of the different disciplines assures overall stability of the institution, where even cancelling the activity of one unit or discipline does not affect the work of the others. Vertically we can group the organisation levels in the HE system at "superstructure" level, that is - the national HE system, "structure" level - the institutional level as a whole (university, college), and "under-structure" levels - the organisation levels of faculty, department, and individual academics. The professional work is done at the under-structure levels, which possess a great deal of decision-making power as to the essential matters of the disciplinary work. The guiding logic at these levels is the logic of the scientific discipline.

The beliefs of the humans working at university are rooted in the scientific truth, pursuing knowledge for its own sake, and discipline loyalty (rather than institutional loyalty). These beliefs are also source of identity, authority, and power. Noteworthy, the shared system of disciplinary and institutional beliefs affects the decision-making processes.

The authority at the institution and under-structure levels reflects the structures of work organisation and beliefs. The substantial part of decisionmaking processes are bottom heavy, made collegially on the basis of professional (disciplinary) and expert judgment; so is the decision-making 
power possessed and exercised. This especially holds true for the disciplinary research and teaching. And despite the significant variety in the power distribution across the different institutions, the under-structure levels have always the final say in deciding on the substance of their professional work.

The innovation and change at under-structure levels occurs mainly on disciplinary grounds - following the changes in the knowledge base, work patterns, and discoveries in the corresponding academic field. On the other hand under-structures are prone to resist other types of change. As Clark (1983; p.207) notes they are primarily responsive to the demands in their scientific fields (other professors), and the large environmental forces as "consumer demand" and "labour-force demand" are largely resisted at that level. In this respect the under-structures differ from the institution management level, which is more responsive to the environmental demands, but in many cases can hardly force the under-structures to take account and implement these demands.

The described change pattern differs from institution to institution and for individual institution over time. In general it can be summarised that (Clark 1983; pp. 202, 209-212):

1. Research universities are inner-directed - first to their research interests, and then, only secondary to the interests of their students and "customers".

2. Teaching and service colleges/institutions, are other way directed.

3. When students are abundant universities tend to follow the internal staff desires and place teaching and services on a take-it-or-leave-it base.

4. When students and resources are in short supply, institutions think more what attracts students and services and are more responsive to the environmental needs.

5. When a new university structure appears (structural change) it tends to appear on a base of discipline specialisation (birth of a new subdiscipline). Interdisciplinary or cross-curricular structures are not highly regarded by the under-structures (this is not generally the case with the institution management level). Such structures tend to be the first "victims" sacrificed in hard times, thus being in unstable position unless managing timely to take roots in the individual institution system of beliefs (see also Bridges 2000; pp.44-48).

6. Change frequently occurs as a result of an intersystem perspective (international transfer is a major route of change).

7. The change, which is translated into prestige and honour for the group as well as the individual, encourages the under-structure clusters to seek and to maintain high rank in the direction of that change. 
In the knowledge economy the production, development and application of new knowledge becomes the main task of more and more people and organizations. HE institutions lose their role as exceptional producers, distributors, and gatekeepers of advanced knowledge. As a consequence, the market is penetrating the HE systems to an extent unseen up to now (Global Symposium on the Future of Higher Education 2001; p.5). Despite that the basic characteristics and patterns of work and changes in the HE systems remain pretty much the same. Addressing the lifelong learning needs of individuals, business, and society is a substantial change process for the HE institutions, ands if we intend this change to occur and take roots in the HE institutions we have to bear in mind the statement of Clark (1983; p.237, emphasis added) that "Desired changes attenuate and fail unless they become a steady part of the structure of work, the web of beliefs, and the division of control".

\section{CIST AS A LIFELONG LEARNING SERVICE PROVIDER}

The structure and organisation of CIST consist of an executive director, advisory council, coordinators, financier, assistants, and a network of experts as temporary contracted staff - researchers, trainers, and design and development specialist (CIST 2002; pp.2-3). At present there are 15 permanent staff, and an operational network of 50 to 70 non-staff experts. CIST works in two main directions - research, and teaching mainly to nonuniversity audience. Some 14 research projects in which CIST has participated have distance learning and e-Learning orientation (CIST 2002; pp. 9-11).

Some of the main groups of training activities of CIST are related to:

- Training public administration and bank employees http://www-it.fmi.uni-sofia.bg/ce/

- Cisco Network Academy Training Program http://www-it.fmi.uni-sofia.bg/ccna/

- Local delivery of the international MSc. programme "Educational and Training Systems Design" (ETSD) of the University of Twente, the Netherlands http://www-it.fmi.uni-sofia.bg/etsd/

The ETSD programme and the research projects of CIST in the domain of learning, play a key strategic role as international scientific "channels" for building CIST" own design \& teaching capacity in human learning, education, and training. 
The Centre also delivers a variety of on-demand courses and training seminars to non-university audience by employing both its own teacher resources and academic staff resources of the university.

The lifelong learning service work of CIST can be schematised as follows:

1. Delivery of specialised training in challenging domains and topics, which requires use of advanced knowledge or application of advanced learning design expertise (to effectively use the advanced knowledge capacity of Sofia University, and to offer challenging training situations as incentives to the contracted university teachers).

2. Active external marketing (the real-market demands) and internal marketing (the possible advanced Sofia University supply).

3. Matching the internal supply to the external demand.

4. Development of CIST capacity for design and delivery of training in Information Society technologies (CIST 2002), and lifelong learning skills.

5. Development of CIST-own delivery infrastructure and facilities (of which the e-learning infrastructure and facilities are of decisive importance).

6. Work, based on the following key characteristics:

- Management \& decision making on business principles;

- Strong incentives to staff and the associated experts;

- Strong leadership (both business and academic);

- Entrepreneurship (see Nikolov 2002);

- Ongoing human and organisation capacity development.

In summary, CIST as lifelong learning delivery structure transforms the academic knowledge supply (advanced discipline-based knowledge and content teaching) into full-fledged lifelong learning market products focused at solving concrete context-based learning problems. In this transformation CIST employs its own expertise capacity, puts "key ingredients", and controls and steers the transformation process. Thus, it is not merely a "transmission" structure, which simply facilitates the organisation and administration of faculty-developed courses, but acts as an interface, in the meaning assumed for this term by the Telecom Glossary 2000 - the American National Standard, T1.523-2001, - "the point of interconnection between two distinct but adjacent communications systems having different functions". 


\section{TOWARDS CONSTRUCTING A MODEL OF LIFELONG LEARNING 'INTERFACE' UNIVERSITY STRUCTURES}

Below we outline a model of 'lifelong learning interface' university structure by describing the key seven critical functions of that structure (besides the "trivial" administrative and organisation functions). The notion is about such a university 'interface' structure, which is aiming at direct service of the lifelong learning market, in a way both to long-term survival within the university, and to be competitive and self-sustainable on the external learning market. The key critical functions are:

1. Business management function

Assures external competitiveness - behaving in the external market the way business behaves. Includes entrepreneurship, strong leadership, financial incentives, judging by performance, profitability, etc. Critical for the external self-sustainability of the 'interface'.

2. Internal (university) politics function

Assures the within-university long time survival. Requires work embedding the 'interface' aims and existence as a steady part of the university structure of work, the web of beliefs, and the division of control. Critical for the long-term survival of the 'interface'.

3. Marketing function (internal and external)

Accounts for the proper transformation of the university "supply" advanced knowledge and teaching, in ready for use marketable learning products. Bi-directional - towards the university "suppliers" (internal), and towards the actual market demand (external). Critical for both assuring internal incentives to the "suppliers" and staff, and assuring external profitability and self-sustainability.

4. Learning design function

Accounts for integration of the market learning demands into the "products" to be offered. Converts mostly content-based academic knowledge into market "outcome" products demanded by the market knowledge, skills and competencies.

5. Teaching (delivery) of lifelong learning skills

Assures acquisition by the learners of skills and competencies needed for learning through life. The regular university teaching does not have as a prime concern these skills (Bridges 2000, pp.44-48).

6. Learning (and particularly e-Learning) infrastructure and facilities May be considered as continuation of the learning design function. Having or sustainable contracting of such infrastructure assures the physical delivery of the training and learning. Crucial for conducting the training/learning. 
7. Strategic internal HRD function

Accounts for the continuous development of the internal and external expert staff. It is a part of the market competitiveness, and internal incentives policy. Critical in dealing with knowledge experts.

\section{CONCLUSION}

The outlined model does not have broad coverage and is not a universal solution to the issue with the higher education institutions approaching (or being approached by) the lifelong learning market. We constrained ourselves within the case of a "classical" university which combines both research and teaching. Also, we bear in mind that such a 'grass-root' and partial approach may look temporary and is not comprehensive in the sense of moving at once the whole university towards lifelong learning demands. Even so, we believe that the current situation of transition of education needs feasible current solutions; and that it is highly unlikely that a comprehensive strategy for quickly turning an entire classical university (or whatsoever $\mathrm{HE}$ institution) can succeed. In turn, when regular academic teachers are employed to work with 'interface' lifelong learning structures, it is highly possible that they will bring lifelong learning design solutions and teaching strategies back to their regular teaching. This is the most convincing and usually met way of implementing innovation and change within the university disciplines.

\section{REFERENCES}

Bridges, D. (2000) Back to the Future: the higher education curriculum in the 21 st century. In: Cambridge Journal of Education, Vol. 30, No 1, 2000, pp. 37-55.

CIST (2002) Best practice case: Centre of Information Society Technologies (CIST) at Sofia University "St. Kliment Ohridski" (http://www-it.fmi.uni-sofia.bg/cist_last.doc)

Clark, B. (1983) The Higher Education System. Academic Organization in Cross-National Perspective. University of California Press, Berkeley, California, USA.

Commission of the European Communities (2000) A Memorandum on Lifelong Learning. Brussels, 30.10.2000, SEC(2000) 1832.

European Commission (2001) Making a European Area of Lifelong Learning a Reality. Communication, COM (2001) 678 final. 
European Commission (2002) European Report on Quality Indicators of Lifelong Learning. Fifteen Quality Indicators. EC, Directorate-General for Education and Culture, Brussels, June 2002.

Global Symposium on the Future of Higher Education (2001) Final Report of "Privileges Lost, Responsibilities Gained: Reconstructing Higher Education”. Columbia University Teachers College, June 14-15, 2001.

(http://www.futuresproject.org/publications/privileges_final.pdf)

Nikolov, R. (2003) Towards Education and Training as a Meta-Industry. Paper presented at the Knowledge Economy Forum II "Implementing Knowledge Economy Strategies" organised by the World Bank and the Government of Finland, Helsinki, March 25-28, 2003.

(http://www.worldbank.org/eca/helsinki/torstai/ilpotapio/bulgaria/ie.html)

World Bank, (2002a) Constructing Knowledge Societies: New Challenges for Tertiary Education. A World Bank report, Washington, D.C.

(http://www1.worldbank.org/education/tertiary/lifelong.asp)

World Bank, (2002b) Lifelong Learning in the Global Knowledge Economy: Challenges for Developing Countries. World Bank, Washington D.C.

(http://www1.worldbank.org/education/pdf/Lifelong\%20Learning_GKE.pdf) 